\title{
Medico-Legal Age Estimation in a Sub-adult Portuguese Population: Validation of Atlas Schour and Massler and London
}

\author{
Cesário $C^{1}$, Santos $R^{2,5}$, Pestana $D^{3,5}$ and Palmela Pereira $C^{4,5,6^{\star}}$ \\ ${ }^{1}$ Faculty of Dentistry, University of Lisbon \\ ${ }^{2}$ Department of Mathematics, School of Technology and Management, Polytechnic Institute of Leiria \\ ${ }^{3}$ Department of Statistics and Operation Research, Faculty of Sciences, University of Lisbon \\ ${ }^{4}$ Faculty of Dentistry, University of Lisbon, Scientific Consultant of Forensic Dentistry, National Institute of Legal Medicine and Forensic Sciences \\ ${ }^{5}$ Centre of Statistics and Applications of University of Lisbon (CEAUL) \\ ${ }^{6}$ Forensic Medicine at Laboratory of Forensic Sciences and Psychological Egas Moniz
}

\begin{abstract}
Introduction: Age estimation in children and adolescents often depends on morphological methods, such as examination of dental development.
\end{abstract}

Objectives: The aim of this project was to validate, in a Portuguese population, two forensic methods of dental age estimation - Schour and Massler charts and the London atlas.

Materials and Methods: The test sample was composed by 108 dental radiographs of living and known-age individuals. Dental age was estimated according to each method. Chronological age was then compared to the estimated dental age using individual t-test and paired t-test

Results: Results showed that the Schour and Massler charts underestimated age and the London atlas overestimated age. Nevertheless, the London atlas performed better in all measures. Mean differences for both the London atlas and Schour and Massler were 0,1389 and -5,4167 months respectively. Schour and Massler charts showed significant statistical difference between dental age and chronological age $(p<0.05)$.

Discussion and Conclusions: We conclude that, in the evaluated sample, age estimation using the London atlas represents an improvement in forensic age estimation from developing teeth. Further studies should be done with a larger Portuguese population sample.

Keywords: Age estimation; Forensic dentistry; Dental age; Schour and Massler charts; London atlas; Portuguese sub-adult population

\section{Introduction}

Forensic age estimation in sub-adults, which can be defined as children, adolescents and young adults who have not reached complete development, has been requested transversally by the authorities using dental age [1]. Dental age can be estimated by observing the morphological stages of tooth mineralization $[2,3]$. There are numerous methods that use dental development to estimate age. Some compare the mineralization stage confirmed in radiographs with standardized schemas or diagrams - atlases based methods [4]. The first atlas based method in forensic age estimation was developed by Schour and Massler in 1941 (and modified by the authors in 1944) [5,6]. The most recent one is the London atlas developed in 2010 [7].

\section{Objectives}

The main objective was to estimate the chronological age of a subadult Portuguese population by applying two dental methods used in forensic age estimation: Schour and Massler atlas and the London atlas. Additionally, we proposed to compare the two dental methods and determine which one is the most accurate when applied to a Portuguese sub-adult population.

\section{Material and Methods}

The study was conducted in two phases: a selection phase and a laboratorial phase. In the first one, 108 panoramic dental radiographs, taken at the Radiological Clinic (University of Lisbon - College of Dentistry) from patients aging between 7 and 21 years, were selected to participate in this research according to the inclusions criteria. The number of males and females selected for each age category was the same. In the second phase the data was analysed and each radiograph classified according to dental development and position. Age was then estimated using Schour and Massler atlas and the London atlas. After one month, $29 \%$ of the observations were repeated to assess intraevaluator variability. Data was submitted to statistical analysis with SPSS for Windows (22.0), with an inclusion level $\mathrm{p}<0.05$. The tests applied were normality tests and T Student for paired samples.

\section{Results}

\section{Kappa agreement}

Kappa values were calculated for each side of the jaw and show almost perfect agreement for the two methods. These results reveal excellent reproducibility for both methods (Figure 1)

*Corresponding author: Palmela Pereira C, Auxiliary Professor, Denta Faculty, University of Lisbon, Portugal, Scientific Consultant of Forensic Dentistry at INMLCF, South Branch, Lisbon, Portugal, Director of the Forensic Medicine Service at Forensic Sciences and Psychologist Laboratory Egas Moni, Tel: 00351914796217; E-mail: cristiana.pereira@fmd.ul.pt

Received May 11, 2016; Accepted May 30, 2016; Published June 06, 2016

Citation: Cesário C, Santos R, Pestana D, Pereira CP (2016) Medico-Legal Age Estimation in a Sub-adult Portuguese Population: Validation of Atlas Schour and Massler and London. J Civil Legal Sci 5: 196. doi:10.4172/2169-0170.1000196

Copyright: $\odot 2016$ Cesário C, et al. This is an open-access article distributed unde the terms of the Creative Commons Attribution License, which permits unrestricted use, distribution, and reproduction in any medium, provided the original author and source are credited. 
Citation: Cesário C, Santos R, Pestana D, Pereira CP (2016) Medico-Legal Age Estimation in a Sub-adult Portuguese Population: Validation of Atlas Schour and Massler and London. J Civil Legal Sci 5: 196. doi:10.4172/2169-0170.1000196

Page 2 of 3

\section{Difference between methods}

Results show significant difference between estimated age provided by Schour and Massler's atlas and the London atlas (Table 1).

\section{Estimated age and chronological age}

Results show statistically significant difference between

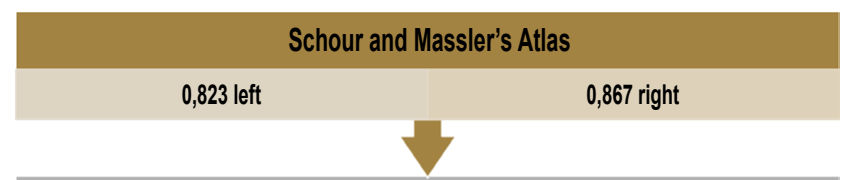

0,925 left

\section{The London Atlas}

$\begin{array}{ll} & \text { The London Atlas } \\ 0,925 \text { left } & 0,925 \text { left }\end{array}$

Figure 1: Intra-observer agreement for both methods (Kappa Agreement). chronological age and estimated age obtained with Schour and Massler's atlas $(\mathrm{p}<0.05)($ Table 2$)$.

Results show no statistically significant difference between chronological age and estimated age obtained with the London atlas (p>0.05) (Table 3).

\section{Estimated age and chronological age difference}

Results show that Schour and Massler's atlas under-estimated age by approximately 5.4 months ( $>0.05)$ (Table 4$)$. The London atlas over-estimated age by around 0.1 months $(p>0.05)$ (Table 5$)$.

\section{Estimated age by gender}

Results show that Schour and Massler's atlas under-estimated age independent of gender. The London atlas under-estimated age in females; and for males over-estimated the age. However, the results of

\begin{tabular}{|c|c|c|c|c|c|c|}
\hline & \multicolumn{5}{|c|}{ Paired Differences } \\
\hline & Mean & SD & $\begin{array}{c}\text { Standard Error } \\
\text { Mean }\end{array}$ & $\begin{array}{c}\text { 95\% Confidence Interval of } \\
\text { the Difference }\end{array}$ \\
\cline { 3 - 6 } & Lower & Upper \\
\hline $\begin{array}{c}\text { Estimated age Schour (left)- } \\
\text { Estimated age London(left) }\end{array}$ & $-5,556$ & 16,152 & 1,554 & $-8,637$ & $-2,474$ & $-3,574$ \\
\hline $\begin{array}{c}\text { Estimated age Schour } \\
\text { (right side)-Estimated age } \\
\text { London(left) }\end{array}$ & $-5,551$ & 16,723 & 1,617 & $-8,757$ & $-2,346$ & $-3,434$ \\
\hline
\end{tabular}

Table 1: T test results for paired differences between estimated age obtained with each method.

\begin{tabular}{|c|c|c|c|c|c|c|c|c|}
\hline & \multicolumn{7}{|c|}{ Paired Differences } & \multirow{3}{*}{$P$ value } \\
\hline & \multirow[t]{2}{*}{ Mean } & \multirow[t]{2}{*}{ SD } & \multirow{2}{*}{$\begin{array}{c}\text { Standard Error } \\
\text { Mean }\end{array}$} & \multicolumn{2}{|c|}{$\begin{array}{l}\text { 95\% Confidence Interval of } \\
\text { the Difference }\end{array}$} & \multirow[t]{2}{*}{$\mathbf{t}$} & \multirow[t]{2}{*}{ df } & \\
\hline & & & & Lower & Upper & & & \\
\hline $\begin{array}{l}\text { Chronological age in months- } \\
\text { Estimated age Schour (left) }\end{array}$ & 5,417 & 24,001 & 2,309 & 0,838 & 9,995 & 2,345 & 107 & 0,021 \\
\hline $\begin{array}{l}\text { Chronological age in months } \\
\text {-Estimated age Schour (right) }\end{array}$ & 5,417 & 24,001 & 2,309 & 0,838 & 9,995 & 2,345 & 107 & 0,021 \\
\hline
\end{tabular}

Table 2: T test results for the paired differences between chronological and estimated age by Schour and Massler's atlas, in months.

\begin{tabular}{|l|c|c|c|c|c|c|}
\hline & \multicolumn{3}{|c|}{ Paired Differences } \\
\hline & Mean & SD & Standard Error Mean & $\begin{array}{c}95 \% \text { Confidence Interval of } \\
\text { the Difference } \\
\text { Lower }\end{array}$ & Upper \\
\hline $\begin{array}{c}\text { Chronological age in months- } \\
\text { Estimated age London (left) }\end{array}$ & $-0,139$ & 15,683 & 1,509 & $-3,131$ & 2,853 & $-0,092$ \\
\hline $\begin{array}{c}\text { Chronological age in months } \\
\text {-Estimated age London(right) }\end{array}$ & $-0,131$ & 15,569 & 1,505 & $-3,115$ & 2,853 & $-0,087$ \\
\hline
\end{tabular}

Table 3: $T$ test results for the paired differences between chronological and estimated age by the London atlas, in months.

\begin{tabular}{|l|c|c|c|c|}
\hline & N & Minimum & Maximum & Mean \\
\hline Schour and Massler error & 108 & $-73,00$ & 46,00 & $-5,4167$ \\
\hline
\end{tabular}

Table 4: Mean error between estimated age and chronological age for Schour and Massler atlas.

\begin{tabular}{|c|c|c|c|c|}
\hline & N & Minimum & Maximum & Mean \\
\hline London error & 108 & $-51,00$ & 43,00 & 0,1389 \\
\hline
\end{tabular}

Table 5: Mean error between estimated age and chronological age for the London atlas.

\begin{tabular}{|c|c|c|c|c|c|}
\hline & Sex & $\mathbf{N}$ & Mean & Standard Deviation & Standard error mean \\
\hline Schour and Massler error & $\begin{array}{l}\text { Males } \\
\text { Females }\end{array}$ & $\begin{array}{l}54 \\
54\end{array}$ & $\begin{array}{l}-4,2593 \\
-6,5741\end{array}$ & $\begin{array}{l}22,59503 \\
25,48888\end{array}$ & $\begin{array}{l}3,07479 \\
3,46860\end{array}$ \\
\hline London error & $\begin{array}{l}\text { Males } \\
\text { Females }\end{array}$ & $\begin{array}{l}54 \\
54\end{array}$ & $\begin{array}{c}2,4074 \\
-2,1296\end{array}$ & $\begin{array}{l}15,25942 \\
15,91374\end{array}$ & $\begin{array}{l}2,07654 \\
2,16559\end{array}$ \\
\hline
\end{tabular}

Table 6: Mean error between estimated age and chronological age discriminated for males and females in both methods. 
Citation: Cesário C, Santos R, Pestana D, Pereira CP (2016) Medico-Legal Age Estimation in a Sub-adult Portuguese Population: Validation of Atlas Schour and Massler and London. J Civil Legal Sci 5: 196. doi:10.4172/2169-0170.1000196

estimated age by London atlas were closer from chronological age in both males and females (Table 6) more accurate.

\section{Discussion and Conclusions}

The London atlas revealed a better performance and more accurate than Schour and Massler's atlas: with minor mean error and showed no statistically significant difference between estimated age and chronological age. The London atlas presents more advantages to be applied as an indicator of chronological age with application at clinical dentistry and forensic dentistry. Regarding the sample size of this research, nevertheless, is not minor than the original one applied to design the London Atlas [7], further studies shall be done in order to create new diagrams only for the Portuguese population. However, the diagrams present by London Atlas must be preferred for the Portuguese Population rather than the older Schour and Massler's Atlas.

\section{Acknowlegment}

Fundação Nacional para a Ciência e Tecnologia, Portugal - FCT under the project (PEst-OE/MAT/UI0006/2014).

\section{References}

1. Willems $G$ (2001) A review of the most commonly used dental age estimation techniques. The Journal of forensic odonto-stomatology 19: 9-17.

2. Feijóo G, Barbería E, De Nova J, Prieto JL (2012) Dental age estimation in Spanish children. Forensic science international 223: 371.

3. Feijóo G, Barbería E, De Nova J, Prieto JL (2012) Permanent teeth development in a Spanish sample. Application to dental age estimation. Forensic science international 214: 213.

4. AlQahtani SJ, Hector MP, Liversidge HM (2014) Accuracy of dental age estimation charts: Schour and Massler, Ubelaker and the London Atlas. Am J Phys Anthropol 154: 70-78.

5. Schour I, Massler M (1941) The development of the human dentition. Journal of the American Dental Association 28: 1153-1160.

6. AIQahtani SJ, Hector M, Liversidge H (2010) Brief communication: the London atlas of human tooth development and eruption. American Journal of Physical Anthropology 142: 481-490.

7. AlQahtani SJ (2012) The London Atlas: developing an atlas of tooth development and testing its quality and performance measures. Institute of Dentistry at Barts and The London School of Medicine and Dentistry, Queen Mary, University of London, UK.
Citation: Cesário C, Santos R, Pestana D, Pereira CP (2016) Medico-Legal Age Estimation in a Sub-adult Portuguese Population: Validation of Atlas Schour and Massler and London. J Civil Legal Sci 5: 196. doi:10.4172/21690170.1000196
OMICS International: Publication Benefits \& Features

Unique features:

Increased global visibility of articles through worldwide distribution and indexing

Showcasing recent research output in a timely and updated manner

Special issues on the current trends of scientific research

Special features:

- $700+$ Open Access Journals

$50,000+$ editorial tean

Rapid review proces

Quality and quick editorial, review and publication processing

Indexing at major indexing services

Sharing Option: Social Networking Enabled

Authors, Reviewers and Editors rewarded with online Scientific Credits

Better discount for your subsequent articles

Submit your manuscript at: http://www.omicsonline.org/submission 